\title{
Pibid arte: espaço contra-hegemônico na formação docente inicial e continuada
}

Pibid art: counter-hegemonic space in initial and continuing teaching training

Arte pibid: espacio contrahegemónico en la formación docente inicial y continua 


\section{Resumo}

O artigo é um recorte das análises preliminares acerca das ações do Pibid Arte da Universidade Federal do Vale do São Francisco, submetido ao Edital 02/2020. O intuito é demonstrar a importância do programa na qualificação do trabalho docente a partir do diálogo entre a formação inicial e continuada a partir do pressuposto de que suas ações atuam de forma contra-hegemônica ao modelo vigente de formação docente no Brasil. Fundamentado na Pedagogia Histórico-Crítica, o Pibid Arte, proporcionou aos/bolsistas e supervisores/a, no período de outubro de 2020 a abril de 2021, procedimentos metodológicos tais como: estudos sistematizados com leituras, palestras, observação da realidade escolar no ensino remoto, relatórios com o objetivo de analisar a dinâmica institucional, pedagógica e política que envolve a práxis docente. Os primeiros resultados apontam a incorporação de algumas atitudes a saber: a. prática investigativa sobre a realidade escolar e o contexto social e histórico dos estudantes; b. uma aproximação maior dos/as bolsistas com a escrita acadêmica; c. para o/a supervisor/a, registro e revisão da prática pedagógica; $d$. o reconhecimento do papel da escola e do professor na sistematização dos conhecimentos para a formação humana, destacando o ensino de arte e a especificidade de seus conteúdos. Por fim, conclui-se que o Pibid Arte é um espaço diferenciado para pensar as políticas de formação docente em Arte, sobretudo, se constituindo em um movimento de resistência contra a precarização do trabalho pedagógico em curso no país demonstrando possibilidades de pesquisas vindouras para o fortalecimento da docência.

Palavras-chave: Formação Docente. Pibid. Contra-hegemonia. Ensino de Arte.

\section{Abstract}

The article is an excerpt of the preliminary analyzes about the actions of Pibid Arte of the Federal University of Vale do São Francisco, submitted to the notice 02/2020. The aim is to demonstrate the importance of the program in the qualification of teaching work based on the dialogue between initial and continuing education based on the assumption that its actions act in a counter-hegemonic way to the current model of teacher's education in Brazil. Based on Historical-Critical Pedagogy, Pibid Arte provided, in the period from October 2020 to April 2021, methodological procedures such as: systematized studies with readings, lectures, observation of school reality in remote education, reports with the objective of analyzing the institutional, pedagogical and political dynamics that involve the teaching praxis. The first results point to the incorporation of some attitudes, namely: A. investigative practice on the school reality and the students' social and historical context; B. a greater approxima-

1 Doutora em Sociologia. Professora do curso de Artes Visuais e do ProfSocio da Univasf, PE. Líder do Núcleo de Ensino de Artes Visuais/Cnpq. Lattes: http://lattes.cnpq.br/1067089791136596. ORCID https://orcid.org/00000002-8363-1670. E-mail: janedalva.gondimaunivasf.edu.br. 
tion of scholarship holders to academic writing and the need for records of pedagogical practices; C. For the supervisor, record and review of the pedagogic practice; $D$. the recognition of the role of the school and the teacher in the systematization of knowledge for human development, highlighting the teaching of art and the specificity of its contents. Finally, it is concluded that Pibid Arte is a differentiated space to think about teacher education policies in Art, above all, constituting a movement of resistance against the precariousness of pedagogical work in progress in the country, demonstrating possibilities for future research for the strengthening of teaching.

Keywords: Teacher Training. Pibid. Counter-hegemony. Teaching of Art.

\section{Resumen}

El artículo es un extracto de los análisis preliminares sobre las acciones de Pibid Arte de la Universidad Federal do Vale do São Francisco sometidos a la convocatoria 02/2020. El objetivo es demostrar la importancia del programa en la calificación del trabajo pedagógico a partir del diálogo entre la educación inicial y continua a partir del supuesto que sus acciones actúan de manera contrahegemónica al modelo actual de formación docente en Brasil. Con base en la Pedagogía Histórico-Crítica, Pibid Arte brindó, en el período de octubre de 2020 a abril de 2021, procedimientos metodológicos tales como: estudios sistematizados con lecturas, conferencias, observación de la realidad escolar en educación remota, informes con el objetivo de analizar las dinámicas institucionales, pedagógicas y políticas que involucran la praxis docente. Los primeros resultados apuntan a la incorporación de algunas actitudes, a saber: A. Práctica investigativa sobre la realidad escolar y el contexto social e histórico de los estudiantes; B. una mayor aproximación de los becarios a la redacción académica y la necesidad de registros de prácticas pedagógicas; C. para el supervisor, el registro y la revisión de la práctica pedagógica; D. el reconocimiento del papel de la escuela y el docente en la sistematización del conocimiento para el desarrollo humano, destacando la enseñanza del arte y la especificidad de sus contenidos. Finalmente, se concluye que Pibid Arte es un espacio diferenciado para pensar las políticas de formación docente en Arte, sobre todo, constituyendo un movimiento de resistencia contra la precariedad del trabajo pedagógico en curso en el país, demostrando posibilidades de investigación futura para el fortalecimiento de la docencia.

Palabras clave: Formación de Profesores. Pibid. Contra Hegemonía. Enseñanza del arte. 


\section{Introdução}

O Programa Institucional de Bolsas de Iniciação à Docência (Pibid) foi instituído pela Portaria Normativa no 38, de 12 de dezembro de 2007, numa ação conjunta entre Ministério da Educação (MEC), da Coordenação de Aperfeiçoamento de Pessoal de Nível Superior - (CAPES) e do Fundo Nacional de Desenvolvimento da Educação (FNDE) em resposta ao déficit apontado pelo Censo do Magistério de 2007 sobre o número significativo de professores da Educação Básica com formação específica, sobretudo, nas ciências exatas².

Diante do desafio de atender a demanda de formação docente, o Pibid acaba ganhando status de uma política de Estado, ao inaugurar nos seus primeiros anos, uma modalidade inovadora de formação inicial e continuada ${ }^{3}$ de professores a partir do diálogo contínuo entre as instituições de Ensino Superior e a Educação Básica contribuindo sobremaneira para melhoria da qualidade da escola pública, conforme relatos verificados no Relatório de Gestão da DEB/CAPES de 2009-20124.

Contudo, nos últimos cinco anos, o Pibid vem sofrendo uma gradativa descaracterização e desvalorização, sobretudo, com as Portarias no 46, de 11 de abril de 2016, n ㄴ 45, de 12 de março de 2018 e, a vigente, nำ 259, de 17 de dezembro de 2019, que buscam transformar o programa em um instrumento da "Política Nacional de Formação de Professores" proposto pelo Ministério da Educação/MEC em 2017"5 com contornos distintos do seu objetivo inicial como podemos verificar no recente Edital № 2/2020.

No Edital em tela houve uma drástica redução no orçamento do programa além de indicar as áreas de atuação do programa como prioritárias e não prioritárias $^{6}$, não apresentando os critérios e as justificativas para essa separação.

2 Ao ser lançado, em 2007, a prioridade de atendimento do Pibid eram as áreas de Física, Química, Biologia e Matemática para o Ensino Médio, dada a carência de professores nessas disciplinas. No entanto, com os primeiros resultados positivos, as políticas de valorização do magistério e o crescimento da demanda, a partir de 2009, o programa passou atender a toda a Educação Básica, incluindo educação de jovens e adultos, indígenas, campo e quilombolas.

3 Segundo Filho (2010, p.6), por formação inicial entende-se um preparo do futuro profissional por meio de um currículo sistematicamente organizado que contemple os conteúdos teóricos e práticos que formem a identidade deste profissional tendo em vista as funções que irá desempenhar nas diferentes possibilidades de trabalho. Já a formação continuada caracteriza-se pela atualização, complementação e/ou aprofundamento de conteúdos relacionados à pratica educativa em suas diferentes dimensões.

\section{Capes. Relatório de Gestão DEB: 2009-2012. Brasília: CAPES, 2015a; b, v. 1 e 2.}

5 O MEC lançou em 2017 a Política Nacional de Formação de Professores alinhada ao projeto ideológico do novo governo a qual abrange desde a criação de uma Base Nacional Docente até a ampliação da qualidade e do acesso à formação inicial e continuada de professores da Educação Básica, tendo como carro-chefe o Programa de Residência Pedagógica reverberando também na reestruturação do Pibid veiculando em seus editais a obrigatoriedade de trabalharem com a Base Nacional Comum Curricular/BNCC.

6 As áreas de Língua Portuguesa, Matemática, Ciências, Física, Química, Biologia e Alfabetização foram apontadas como áreas prioritárias enquanto que as áreas de Arte, Educação Física, Língua Inglesa, Língua Espanhola, Geografia, História, Sociologia, Filosofia e as licenciaturas Intercultural Indígena, em Educação do Campo e em Pedagogia foram consideradas áreas gerais e não prioritárias. 
A partir do momento em que há a redução orçamentária do programa e uma cisão das áreas de conhecimento entre prioritárias e não prioritárias, destinando maior recurso para áreas consideradas prioritárias, o edital incentiva a desvalorização das áreas das humanidades e das artes na formação humana alimentando o discurso tecnicista e pragmático na educação, ou seja, o extremo oposto da meta inicial do programa.

Paralelo às questões apresentadas, o estado de pandemia em função da COVID-19 decretado pela Organização Mundial da Saúde em março de 2020 e o fechamento das escolas interrompendo as aulas presenciais mudando a rotina de 1,5 bilhão de estudantes e de 63 milhões de professores de Educação Básica, em mais de 165 países, segundo dados da UNESCO (2020), acelerou a precarização do trabalho docente com a adoção do ensino remoto emergencial.

Estas condições repercutiram na educação de modo avassalador e problemático, em especial, no trabalho pedagógico em virtude de que até o momento tínhamos somente a experiência de ensino a distância (ou EaD) na Educação Superior e pouca ou nenhuma ação na Educação Básica, e de modo abrupto, professores e estudantes se viram diante de uma imposição de nova configuração dos modos de ensinar e aprender impostos pelo ensino remoto.

Diante desta realidade de mudanças sobre as finalidades do programa e do ensino remoto, o Pibid vem resistindo as disputas e permanecendo como um lócus privilegiado de formação de professores se constituindo, no nosso ponto de vista, um espaço contra- hegemônico nas disputas pelo modelo de formação docente vigentes no país.

A seguir discutiremos o entendimento do Pibid como espaço contra-hegemônico de formação docente, em seguida, abordaremos, pautado na Pedagogia Histórico-Crítica, o contexto e os desafios da realização do Pibid Arte diante do ensino remoto e por fim, as análises preliminares do projeto.

\section{Pibid: espaço contra-hegemônico na formação de professores}

O Pibid como política pública, como mencionado anteriormente, ganhou significativa atuação no aperfeiçoamento e na valorização da carreira docente que, pela primeira vez apresentou a formação de professores subsidiada de maneira sólida (GATTI; BARRETO; ANDRÉ, 2011) para além das fronteiras da universidade e de forma distinta do estágio supervisionado.

Nesse sentido, o Pibid, segundo Felício (2014) se constitui em um terceiro espaço de formação por possibilitar que o coordenador atue como um mediador na transição do espaço de formação (Instituição de Ensino Superior, IES) e atuação (Escola da Educação Básica). Nessa relação, o supervisor se torna um coformador dos e das pibidianos/as e o/a futuro/a professor/a vivenciando o ambiente profissional ainda na graduação, por meio do planejamento, estudo de metodologias e o conhe- 
cimento de diferentes realidades de escolas da Educação Básica, da interação com alunos, professores, gestores, entre outros.

Contudo, a partir das ameaças de mudanças do Pibid que iniciaram em 2015 e que vem se concretizando, o mesmo, vem deixando de ter como foco principal, a formação inicial de professores e passa a ter como objetivo melhorar o Índice de Desenvolvimento da Educação Básica/IDEB das escolas, transformando a iniciação à docência em processo de aula reforço.

Ademais, vale ressaltar que desde os anos 1990, segundo Frigotto (1995), se estabelece no Brasil uma nova base técnico-científica para a reestruturação produtiva do capitalismo, fato que culminou em mudanças políticas, econômicas e culturais em âmbito mundial, intensificada nos últimos anos pela política neoliberal.

Nessa direção, em 1996, surge o Relatório para a Unesco da Comissão Internacional sobre a Educação para o Século XXI, com o título "Educação, um tesouro a descobrir", tendo como protagonista o francês Jacques Delors ${ }^{7}$.

A partir dessa configuração da política educacional brasileira, Dourado (2001, p. 49) explica que a escola se torna um elo entre a socialização dos conhecimentos "técnico-científicos historicamente produzidos pelo desenvolvimento de habilidades, capacidades e competências sociais requeridas, predominantemente, em sintonia com o poder produtivo" reverberando no modelo de formação docente requerido que, antes, privilegiava conhecimentos e saberes teóricos, deslocando-se para uma abordagem que dá ênfase ao saber fazer (utilitário e pragmático), exigido pelo mercado.

No sentido de contrapor-se à visão utilitarista da formação, Saviani (1996) aborda o papel do conhecimento científico para o desenvolvimento do trabalho educativo, considerando sua importância para a compreensão da realidade na qual a prática pedagógica se desenvolve, e seu conteúdo histórico cultural e social, imprescindível ao processo de humanização dos indivíduos.

Neste cenário de disputas sobre os modelos de formação docente e na busca de contrapor-se ao Modelo utilitarista e pragmático empreendido pela política neoliberal entendemos o Pibid como um espaço de resistência, um movimento contra-hegemônico ${ }^{8}$ na medida em que apesar das interferências do neoliberalismo, possibilita licenciandos/as e professores em exercício a articulação de saberes, seja no sentido da prática colaborativa, seja no fazer pedagógico e, inclusive, na própria

7 O documento traz conceitos orientadores à educação, como a ideia de educação permanente e os quatro pilares da educação: aprender a viver juntos, aprender a conhecer, aprender a fazer e aprender a ser. Este texto apresenta o discurso do Estado Liberal, conservador e o que este pretende com a formação de professores. $O$ discurso atende aos interesses do mercado capitalista em relação a formação profissional onde a técnica se sobrepõe à razão.

8 Segundo Dore e Souza (2018), a concepção de contra hegemonia foi cunhada por Raymond Williams em seu livro Base e superestrutura (1978) e posteriormente revisto em Marxismo e literatura (1978). Nesse aspecto, a contra hegemonia adotada nesse texto faz referência a idéia de Williams, de compreendê-la como uma cultura de oposição ou contestação, assim, na nossa concepção o Pibid atuaria de forma contra-hegemônica ao modelo de formação docente dominante. 
profissionalidade ${ }^{9}$ docente. Isto implica dizer, que a interação dos cursos de Licenciatura com as escolas da Educação Básica mediadas pelo Pibid permite colocar em curso diferentes saberes sobre a docência em oposição à visão utilitarista que vem assumindo uma posição hegemônica frente aos modelos de formação docente no país. Sendo assim Saviani (1997, p. 238) nos alerta:

Enquanto prevalecer na política educacional a orientação de caráter neoliberal, a estratégia da resistência ativa será a nossa arma de luta. Com ela nos empenharemos em construir uma nova relação hegemônica que viabilize as transformações indispensáveis para adequar a educação às necessidades e aspirações da população brasileira.

No que se refere especificamente a formação de professores de Arte, os estudos do Observatório ${ }^{10}$, em especial os de Fonseca da Silva; Hillesheim (2013), apontaram que o foco das pesquisas ${ }^{11}$ sobre formação do professor de arte realizados entre 2000 a 2010 se concentrou muito mais nas experiências concernentes ao ensino de Arte na escola e nos relatos de formação continuada do que em estudos acerca da formação de professores nos cursos de graduação.

As autoras questionam a partir dos dados da pesquisa sobre o lugar da arte nos estudos sobre a formação de professores de arte. Que especificidade permeiam a formação deste profissional?

Compreendendo a lacuna sobre estudos referentes a formação de professores de arte nas licenciaturas apontada pelos estudos de Fonseca; Hiillesheim (2013) somados a outros do Observatório, acreditamos que as ações do Pibid Arte, pautadas na perspectiva da Pedagogia Histórico-Crítica, podem atuar como um movimento contra-hegemônico na articulação entre formação inicial e continuada de professores de Arte e assim avançarmos para o fortalecimento das políticas de formação docente.

9 A definição de profissionalidade feita por Ramalho, Nunez e Guathier (2004), citados por Cruz (2012), caracteriza-se como os conhecimentos adquiridos pelo professor para a atividade docente e articula-se dialeticamente com o conceito de profissionalismo que, segundo os mesmos autores, tem a ver com a legitimação, valorização e reconhecimento da profissão perante a sociedade.

10 Observatório de Formação de professores no âmbito do Ensino de Artes Visuais: estudos comparados Brasil e Argentina.

11 O estudo de Fonseca da Silva; Hillsheim trata-se de uma análise histórica a partir de um levantamento bibliográfico em anais de eventos, teses e dissertações, bem como em periódicos da área. 


\section{Pibid Arte e as ações de formação docente em tempos de pandemia}

O curso de licenciatura de Artes Visuais da Univasf participa do Pibid desde 2009 por meio da aprovação do Edital CAPES/DEB № 02/2009 o qual teve a participação de 24 (vinte e quatro) bolsistas de iniciação à docência (licenciandos do curso de Artes Visuais), 02 (dois) professores supervisores (um em cada escola parceira), 01 (um) coordenador de área docente da universidade.

Durante mais de 10 anos o Pibid de Arte vem colaborando com a formação dos professores de Artes Visuais de abrangência da Univasf, tanto no sentido de melhorar sua inserção na carreira docente no que se refere a aprovação de concursos públicos para atuarem nas escolas da região como na continuidade dos estudos acadêmicos, a exemplo do número significativo de egressos que fizeram mestrado, e recentemente, ingressaram no doutorado.

No projeto institucional submetido ao edital 02/2020 intitulado Saberes docentes e Currículos escolares buscamos problematizar o reconhecimento da complexidade que envolve a constituição do sujeito professor e dos saberes escolares, em particular, o estudo sobre a BNCC juntamente com os conteúdos escolares das áreas de conhecimento oferecidas pelas Licenciaturas da Univasf, a saber: Ciências da Natureza, Geografia, Educação Física, Química, Ciências Sociais e Artes Visuais.

No que tange ao Subprojeto de Arte denominado de Educação em Artes Visuais contextualizada: estratégias para a consolidação da formação buscamos a partir da Pedagogia Histórico-Crítica proporcionar a inserção no trabalho pedagógico no sentido contra-hegemônico na formação inicial e continuada dos professores de Arte.

Uma das primeiras ações do subprojeto de Arte após sua aprovação foi compor a equipe para qual foram selecionados 16 licenciandos/as, sendo seis ingressantes e 10 cursando entre o 3․ e 4․ Semestres, os quais chamaremos de pibidianos/ as. Os dois professores-supervisores selecionados ambos egressos do curso de Artes Visuais, foram pibidanos/a na época de sua graduação, demonstrando o papel significativo deste programa na inserção na carreira docente.

Vale destacar, que estes professores atuam em duas escolas ${ }^{12}$ de realidades distintas da cidade de Juazeiro, Bahia. Uma se localiza em um bairro periférico de população predominante negra enquanto que a outra localizada no bairro Horto Florestal é administrada por gestores da Polícia Militar.

Após a seleção da equipe foi preciso reorganizar os estudos de formação considerando o estado da pandemia e o ensino remoto que se instaurou nas práticas educativas como condição sine qua non. Embora indefinições do Ministério da Educação e das pressões da Capes para atividades presenciais, entendemos que o Pibid se constituía como uma ótima oportunidade para a ressignificação da escola e dos modelos de formação docente vigentes.

12 Escola-campo parceiras do Pibid Arte, Colégio Estadual Artur Oliveira da Silva e Colégio Militar Alfredo Viana. 
Assim, o Pibid Arte em razão da pandemia e da suspensão das aulas presenciais na universidade, iniciou suas atividades em outubro de 2020 com reuniões realizadas via plataforma Googlemeet para planejamento e organização das ações de estudo.

Como as escolas-campo onde o Pibid atuaria também não estavam funcionando com aulas presenciais e a falta de encaminhamentos da Secretaria de Educação do Estado da Bahia que somente em 2021 apresentou um plano para o ano letivo de 2020 e 2021 de modo continum ${ }^{13}$ decidimos priorizar os encontros em estudos sistematizados em torno de 03 princípios-ação para pensar a formação docente na perspectiva contrahegemonica: 1. O conceito de práxis; 2. A Pedagogia Histórico-Crítica/PHC e o ensino de Artes Visuais; 3. O objeto do ensino de Arte na PHC.

Dessa forma, de outubro à dezembro de 2020 realizamos a primeira ação com a colaboração da professora Dra Consuelo Schilichta que se destinou a promover uma reflexão sobre a arte como práxis humana e qual seria o objeto do ensino de Artes Visuais.

As intervenções da profa Consuelo Schilichta baseadas nas ideias Adolfo Sánchez Vázquez (2011) e suas leituras, provocaram os/as licenciandos/as a problematizar a arte e seu ensino a partir da práxis humana no sentido dialético entre teoria e prática, objetividade criada na e pela subjetividade. Isto implica assumir o entendimento da arte como uma ação/experiência de sentidos da vida humana.

Vázquez distingue diferentes níveis de práxis, postulando com base nos critérios de consciência e criatividade do indivíduo, uma práxis criadora ${ }^{14}$ e a reiterativa ou imitativa por um lado, e por outro a práxis reflexiva e espontânea. Nos interessa em particular o entendimento da arte como ação humana, tomada como práxis criadora, para pensar o ensino de Arte pautada em um paradigma epistemológico que situe a criação no entremeio da reflexão e ação do processo contínuo da experiência humana.

Aprofundando a questão da práxis criadora, a segunda ação, propomos aos/ às pibidianos/as estudarem a Psicologia Histórico Cultural a partir da leitura do livro "Imaginação e criação na Infância" o qual foi apresentado em grupo no formato de Seminário online.

A idéia foi discutir a perspectiva de Vigostki sobre a atividade criadora e sua relação com o ensino de Artes Visuais. Considerando esses aspectos como pensar a atividade criadora no contexto do ensino remoto. É possível? De que maneira?

No relatório mensal, um pibidiano escreveu:

13 O currículo continum foi apresentado em março de 2021 pela Secretaria de Educação do Estado da Bahia como forma de atender a obrigatoriedade dos dias letivos de 2020 juntamente com os de 2021. Assim, a proposta consisti na realização do ano letivo 2020 e 2021 em único ano

14 Para Vázquez (2011), a ação criadora é determinante, pois possibilita ao indivíduo enfrentar novas necessidades ou situações e criar novas soluções. Na ação do homem sobre o mundo, há uma alternância entre ação criadora e a permanência, convivendo constantemente com a imitação, com a reiteração, numa íntima relação entre as dimensões subjetivas e objetivas, entre o planejado e o realizado. Criar significa idealizar e realizar o que foi pensado, refletido. Na práxis criadora, reflexão e ação se dão de maneira simultânea em um processo constante de mudanças e correções ao longo da jornada. 
Diante da situação de pandemia no país, os estudos sobre Vigotski e especialmente o livro 'Imaginação e criação na infância', traduzido por Zoia Prestes e apresentado e comentado por Ana Luiza Smolka, me fizeram pensar em como é necessário fugir da perspectiva convencional do ensino das artes. Ao contrário do que é muito dito pelo senso comum, a imaginação e criatividade estão fortemente ligadas à realidade e imagino que é a partir delas que devemos trilhar um caminho diferente para que possamos ensinar as artes de forma que os alunos absorvam os conteúdos com mais facilidade e afetividade. (Pibidiano 1, Relatório Mensal de janeiro 2021)

No depoimento do pibidiano pudemos perceber uma reflexão acerca da noção vulgar de imaginação ou criatividade que cerca o entendimento e as práticas de ensino na área de Artes Visuais, em especial, demonstrando o interesse em aprofundar o estudo na busca por superar o senso comum sobre essa questão. Ademais o Pibidiano 1 problematiza o conceito de atividade criadora e seu aspecto coletivo da criação humana:

A atividade criadora é tão velha quanto nossa presença neste planeta. Caminhamos ao seu lado em passos sincrônicos, ou melhor, nós habitamos nela e fazemos dela uma condição necessária de existência. Ela está em cada cotidiano, seja no trabalho anônimo que torna o objeto palpável ou na produção emocional - essa sensibilização que faz de nós humanos. Quantas imaginações foram precisas para criar esperança? (Pibidiano 1, Relatório Mensal de janeiro 2021)

Com esses relatos é possível compreender o processo de aprendizagem dos bolsistas ao incorporarem em suas falas o entendimento sobre atividade criadora como uma capacidade ontológica que se materializa por meio do trabalho, ou seja, "os objetos da vida diária, mesmo que simples e habituais, que correspondem à criação anônima coletiva dos inventores anônimos, são fantasia cristalizada (VIGOSTKI, 2009, p. 10).

Do mesmo modo, é possível compreender que "no decurso da atividade dos homens, as suas aptidões, os seus conhecimentos e o seu saber-fazer cristalizam-se de certa maneira nos seus produtos, sejam eles materiais, intelectuais ou ideais" (MARTINELLI e ALMEIDA, 2017).

A terceira ação desse bloco, os/as pibidianos/as participaram do Ciclo de Debates: Formação e arte nos processos políticos contemporâneos realizado pelo LIFE/ Udesc, assistindo, em especial, a palestra "As Contribuições da PHC para o ensino de Arte na Escola" proferida pelo Prof. Dr. Newton Duarte (UNESP), e a mesa redonda: "Os Conteúdos Escolares de Artes na Pedagogia Histórico-Crítica", realizada pela Profa. Dra. Consuelo Alcioni Borba Duarte Schlichta (UFPR) e Profa. Dra. Mariana de Cássia Assumpção (UFG). 
Sobre as contribuições da PHC para o ensino de Arte, o Pibidiano 12 analisa no seu relatório mensal de fevereiro:

\begin{abstract}
As palestras sempre são bastante enriquecedoras, para mim é inspirador ver tantos profissionais verdadeiramente empenhados em suas carreiras e tão dispostos a compartilhar suas experiências. Houve questões que me chamaram atenção como a fala do Dr. Newton Duarte sobre catarse, esse momento de despertar criativo e transformador do conhecimento. (Bolsista 12, Relatório Mensal de janeiro 2021)
\end{abstract}

O contato com a produção de pesquisas na área de formação de professores de Arte possibilita a/os pibidianos/as a compreensão do trabalho pedagógico na perspectiva investigativa, sobretudo, considerando o contexto de precarização do ensino e a busca por uma atitude transformadora.

Nesse aspecto, o estudo da perspectiva da Pedagogia Histórico-Crítica reposiciona o ensino de arte entre os saberes escolares que contribuem para a formação humana numa perspectiva omnilateral, ou seja, uma individualidade livre e universal. Dessa maneira, reconhece o ensino de arte a partir da apropriação da especificidade de seus conteúdos na formação da consciência crítica.

Os/as pibidianos/as e os/as supervisores relataram ainda a dificuldade em compreender os conceitos discutidos por entenderem que são bastantes complexos e que exigem deles mais estudos e uma mudança no pensamento.

Diante dessas colocações, o Pibid entendido como processo que articula a formação inicial e continuada de professores coloca em questão o modelo pragmático e utilitarista na medida em que os sujeitos envolvidos assumem o protagonismo na elaboração de conhecimentos e saberes acerca da docência. O diálogo entre o supervisor/a e o/a pibidiano/a, tendo a escola como fócus de formação, segundo Candau (1988, p.58) favorece os "processos coletivos de reflexão e intervenção na prática pedagógica concreta. Parte-se das reais necessidades dos professores, dos problemas do seu dia-a-dia e favorece-se processos de pesquisa-ação".

Sobre as condições do ensino de Artes Visuais no contexto remoto, a supervisora em entrevista ao Podcast Arte[in]foco ${ }^{15}$ relatou:

Na minha percepção são muito limitantes tanto para os alunos quanto para os professores. Primeiro que a gente tá vivenciando aí um modelo de ensino remoto emergencial, né? Não é um ensino online, não é um ensino à distância. Nem os professores e os estudantes estavam preparados pra esse modelo, essa nova configuração. Nossos materiais didáticos não contemplam esse modelo de ensino, né? Tudo tem que ser adaptado. O maior problema dessa alteração, configuração de ensino foi muito rápida. Não deu tempo

15 A socialização das ações do Pibid está sendo feita pelo Informativo Pibid postado no Instagram do Núcleo de Ensino de Artes Visuais e pelo Podcast Arte[in]foco disponível no Spotify. 
para que os professores passassem por uma formação mais específica sobre como usar essas ferramentas, né? Como programar essas aulas. Existe também essa preparação do estudante que muitas vezes não conhece essas ferramentas, não conhece esses ambientes virtuais. É bem complicado tanto pra quem tá propondo as aulas como para os estudantes que acessam esse material. (Supervisora 1, Transcrição do Podcast março de 2021),

O relato da professora-supervisora no Podcast mostra as dificuldades vivenciadas no período da pandemia da adoção do ensino remoto de modo emergencial que acabou se tornando a única alternativa.

Ainda sobre a mesma problemática, a supervisora, relatou as dificuldades encontradas para os estudantes acessarem o conteúdo planejado. "Os estudantes têm dificuldade de acessar as aulas remotas porque muitos deles não têm wifi, estou vendo uma possibilidade de mesclar atividades pelo Whatsapp e impressas para ver se eles acompanham". (Supervisora 1)

Antes desta problemática apresentada pela professora-supervisora observada no Pibid, Zamperetti (2021) havia verificado em sua pesquisa realizada em 2020 que:

Diversos fatores interferem no desenvolvimento das práticas com TIC na escola, como por exemplo, os problemas de ordem material e física, ou seja, falta de espaço adequado e recursos qualificados à atuação pedagógica, que impedem a utilização das tecnologias por falta de manutenção e oferta de equipamentos.

Os relatos dos professores-supervisores do Pibid confirmam os dados apontados por Zamperetti (2021) no que diz respeito aos problemas enfrentados com o uso das TIC's na escola, que se estendem aos aspectos tecnológicos tanto na posse dos equipamentos quanto ao conhecimento para utilizá-lo como ferramenta didática.

O que foi possível perceber durante o Pibid que a situação do ensino remoto revelou o fosso das desigualdades sociais existente no país uma vez que estas dificuldades não se apresentam de modo tão gritante para os estudantes da escola-campo, Polícia Militar Alfredo Viana/ CPM localizada no bairro Horto Florestal. Embora, em ambos os casos o ensino remoto acaba agravando uma situação desigual de acesso aos bens culturais, que no caso, trata-se da aprendizagem dos conteúdos de Artes Visuais.

De um modo geral, até momento o objetivo do Pibid Arte foi fomentar a reflexão crítica sobre as condições do trabalho docente na pandemia a partir do aporte da PHC, avaliando as possibilidades e entraves para o ensino de Artes Visuais na modalidade remota.

Por fim, entendemos que as ações do Pibid Arte tomados com um movimento contra- hegemônico na formação docente coloca em curso uma potente resistência. 


\section{Considerações Finais}

Esse texto reflete a importância das atividades do Pibid Arte/Univasf na formação de futuros professores na condição de intelectuais orgânicos (GRAMSCl, 1995) na articulação entre formação inicial e continuada.

A partir de leitura de textos, relatórios, participação em evento científico e palestras voltadas às condições de ensino de Artes Visuais na pandemia realizadas nos meses de outubro de 2020 a abril de 2021, buscamos indícios qualitativos para considerar o Pibid como espaço contra-hegemônico ao modelo de formação docente de viés utilitarista em curso no país.

Percebemos, pelos dados apresentados até o momento, que o Projeto tem gerado aprendizagens no que tange à incorporação de algumas atitudes a saber: a. prática investigativa sobre a realidade escolar e o contexto social-histórico dos estudantes da escola pública; b. uma aproximação maior dos/as pibidianos/as com a escrita acadêmica e a necessidade de registros de suas práticas; c. o reconhecimento do papel da escola e do professor na sistematização dos conhecimentos para a formação humana; d. uma melhor apropriação sobre a arte e seus conteúdos.

Esse último, será o ponto que iremos nos direcionar com mais veemência nos próximos meses considerando que a colaboração do Pibid na parceria Escola-Universidade se mostra na conjugação dos diferentes contextos, proporcionando reverberações nos dois campos de atuação para os/as pibidianos/as e seus professores-coordenadores, como também para os professores-supervisores e seus alunos na escola pública, se constituindo um espaço dialógico e dialético de formação de professores.

Os/as bolsistas de iniciação à docência que participam do Pibid Arte foram inseridos no cotidiano escolar afetado pela pandemia e pela realização do ensino remoto provocando muitos questionamentos e análise dessa situação atípica no desafio de lutar pela sobrevivência sem perder de vista este fazer pedagógico. À partir dos relatos apresentados pelos participantes do Programa, foi possível verificar que o/a pibidiano/a vem adquirindo conhecimentos e capacidade crítica sobre a práxis docente, o que contribui para uma reflexão profissional do licenciando, e para uma nova concepção de atuação docente, uma vez que que ele se defronta com as situações reais de ensino e aprendizagem.

Diante do que foi exposto, percebe-se que o Pibid consegue resultados significativos, seja para o/a pibidiano/a que começa a articular meios para transpor o que aprende nas disciplinas teóricas da graduação podendo este ingressar na atividade docente já com vivências mais consistentes e que possam servir de base para a sua futura atuação profissional como para o/a professor/a supervisor/a, pois o Pibid traz a oportunidade da revisão constante de sua prática. Para a formação continuada, constata-se que o ambiente da escola permite tanto ao professor atuante quanto ao professor em formação encontrar um ambiente que permite observar in loco a dinamicidade do processo educativo "neste cotidiano ele aprende, desaprende, re- 
estrutura o aprendido, faz descobertas e, portanto, é nesses lócus que muitas vezes ele vai aprimorando a sua formação" (CANDAU, 1998, p. 57).

Contudo, estamos só no início e vislumbramos possibilidades de futuras pesquisas tanto a nível de trabalho de conclusão de curso como na pós-graduação. 


\section{Referências}

BRASIL. Coordenação de Aperfeiçoamento de Pessoal de Nível Superior. Edital n. 001/2011 CAPES. Programa Institucional de Bolsa de Iniciação à Docência. Editais e seleções. Disponível em: https://www.gov.br/capes/pt-br/acesso-a-informacao/ acoes-e-programas/educacao-basica/pibid/editais-e-selecoes

Acesso em: 14.set. 2016.

Decreto no 7.219, de 24 de junho de 2010. Dispõe sobre o Programa Institucional de Bolsa de Iniciação à Docência - PIBID e dá outras providências. Diário Oficial da União, n. 120, seção 1, p. 4-5, 2010. Disponível em: http://www.planalto.gov. br/ccivil_03/_ato2007-2010/2010/decreto/d7219.htm. Acesso em: 13 jul. 2016.

CAPES. Coordenação de Aperfeiçoamento de Pessoal de Nível Superior. Diretoria de formação de professores da Educação Básica/DEB. Relatório de gestão do PIBID. Brasília, 2013. Disponível em: https://www.capes.gov.br/images/banners/18092018_ Relat\%C3\%B3rio_de_Gest\%C3\%A30_CAPES_2017.pdf . Acesso em: jun. 2019.

Portaria normativa no 260, de 30 de dezembro de 2010. Dispõe da Normas Gerais do Programa Institucional de Bolsa de Iniciação à Docência - PIBID. Disponível em: http://www.capes.gov.br/educacaobasica/capespibiddownload/ Portaria260_PIBID2011_NomasGe- rais.pdf. Acesso em: 13 jul. 2016.

Portaria Normativa no 38, de 12 de dezembro de 2007. Dispõe sobre o Programa Institucional de Bolsa de Iniciação à Docência - PIBID. Diário Oficial da União, n. 239, seção 1, p. 39, 2007. Disponível em: https://www.capes.gov.br/ images/stories/download/legislacao/Portaria_Normativa_38_PIBID. Acesso em: 13 jul. 2016.

Decreto 6755, de 27 de janeiro de 2009. Institui a Política Nacional de Formação de Profissionais do Magistério da Educação Básica, disciplina a atuação da Coordenação de Aperfeiçoamento de Pessoal de Nível Superior - CAPES no fomento a programas de formação inicial e continuada, e dá outras providências. Brasília: MEC, 2009.

Portaria no 46, de 11 de abril de 2016. Aprova o Regulamento do Programa Institucional de Bolsa de Iniciação à Docência - Pibid. Disponível em: https://www.capes.gov.br/images/stories/download/legislacao/15042016Portaria-46-Regulamento-PIBID-completa.pdf Acesso em 23 jul. 2016. 
CANDAU, Vera Maria. Formação Continuada de Professores: Tendências Atuais. In: CANDAU, Vera Maria (org.). Magistério: construção cotidiana. Petrópolis. Rio de Janeiro: Vozes, 1998.

DOURADO, Luiz Fernandes. Diretrizes curriculares nacionais para a formação inicial e continuada dos profissionais do magistério da educação básica: concepções e desafios. Educação \& Sociedade, Campinas, v. 36, n‥ 131, pp. 299-324, abr/jun., 2015.

FELÍCIO, H. M. S. O PIBID como "terceiro espaço" de formação inicial de professores. Revista Diálogo Educacional, v. 14, n. 42, p. 415-434, maio/ago. 2014. Disponível em: https://periodicos.pucpr.br/index.php/dialogoeducacional/article/ view/6587. Acesso em: jun. 2019.

FRIGOTTO, Gaudêncio. Educação e crise do capitalismo real. São Paulo: Cortez, 1995

FONSECA da SILVA, M.C.R. \& HILLSHEIM, G.B.D. Políticas Públicas e formação docente em arte: confluências entre pesquisas. In: Simposio Latinoamericano de Formación de Profesores de Artes, 2013, Bogotá - Colombia. Anais... Bogotá Colômbia: Editora da Universidad Sérgio Arboleda, 2013. p. 253-264.

GRAMSCl, A. Os intelectuais e a organização da cultura. 9. ed. R.J.: Editora Civilização Brasileira, 1995.

GATTI, B. A.; BARRETO, E.; ANDRÉ, M. E. D. A. Políticas docentes no Brasil: um Estado da Arte. Brasília: UNESCO, 2011. 300p.

MARTINELLI, T. A. P.; ALMEIDA, E. M. Contribuições da concepção vigotskiana de arte para o ensino da cultura corporal. Universidade Estadual de Maringá Maringá - PR.

SAVIANI, D. Pedagogia histórico-crítica: primeiras aproximações. 11aㅡ ed. rev. Campinas, SP: Autores Associados, 1997.

SAVIANI, Demerval. Formação de professores: aspectos históricos e teóricos do problema no contexto brasileiro. Revista Brasileira de Educação, v. 14, n. 40, p. 143-155, jan./abr. 2009. www.conedu.com.br Acessado em: 11 de junho de 2021. Disponível em: http://www.scielo.br/pdf/rbedu/v14n40/v14n40a12.

VASQUEZ, Adolfo Sánchez. Filosofia da práxis. 2aㅗ edição- Buenos AIRES: Consejo Latinomericano de Ciências Sociales- CLASCO: São Paulo: Expressão Popular, BRASIL, 2011. 
VIGOTSKI, L. S. Imaginação e criação na infância: ensaio psicológico. São Paulo: Ática, 2009.

ZAMPERETTI, M. P. Artes visuais e ensino remoto:paroxismo nas interações em tempos de pandemia. Palíndromo, v. 13, n. 29, p. 37-53, jan - abril 2021. Disponível https://periodicos.udesc.br/index.php/palindromo/article/view/18977. Acesso em: 14 de fevereiro de 2021

Submetido em 11/08/2021

Aprovado em 22/10/2021 